\title{
PREVENTION OF ACETABULAR EROSION AFTER HEMIARTHROPLASTY FOR FRACTURED NECK OF FEMUR
}

\author{
MICHAEL DEVAS, BARRY HINVES
}

From the Royal East Sussex Hospital, Hastings

\begin{abstract}
The best treatment for a fractured neck of femur in an old person is considered by many to be replacement hemiarthroplasty which allows the patient to walk immediately on a stable, painless hip. The late results can be marred by acetabular erosion in which the metal head of the prosthesis erodes upwards into the acetabulum to give pain and disability.

Here the trial of a new bipolar prosthesis with a dynamic self-aligning outer head is described in 161 fractured necks of femur. No acetabular erosion has been seen with its use over four years.
\end{abstract}

For many years the controversy of fixation or replacement for the fractured neck of femur has continued. Properly done, it is believed that replacement is superior to fixation in the older patient, particularly when rehabilitation after the operation is considered (Devas 1977). Barnes et al. (1976) showed results of pinning fractured femoral necks which had an overall failure rate at six months of 25 per cent, which continued to increase with time. D'Arcy and Devas (1976) showed results that were as good by replacement using the cemented Thompson prosthesis but these figures included the morbidity from acetabular erosion. The incidence of erosion is shown in Figure 1; it is to be noted that the younger the patient the greater the incidence.

Causes of erosion. Acetabular erosion occurs as a result of impact causing injury to the acetabular cartilage at the time of the accident, especially as the elderly often sustain injury by a fall directly on the hip. Excessive pressure on the acetabular cartilage after arthroplasty also produces erosion when insufficient femoral neck is resected in the anxiety to obtain a firm, stable reduction. It is felt that the exact matching of the size of the prosthetic head is particularly important, too large a head producing ring wear of the acetabulum and too small a head increased point bearing with subsequent wear. Finally, the cemented metal implant within the upper part of the femoral shaft will be more likely to transmit the impact of each footfall with greater stress across the prosthesisto-bone interface than would normal bone in which there is considerable resilience.

Professor M. Devas, MChir, FRCS

Orthopaedic Department, School of Medical Sciences, Universiti Sains Malaysia, Penang, Malaysia.

B. Hinves, FRCS, Consultant Orthopaedic Surgeon

Royal East Sussex Hospital, Hastings TN34 IER, England.

Requests for reprints should be sent to $\mathrm{Mr} \mathrm{B}$. Hinves.

(C) 1983 British Editorial Society of Bone and Joint Surgery $0301-620 \mathrm{X} / 83 / 5090 \$ 2.00$

\section{METHOD AND MATERIAL}

The Hastings hip* is a concentric double-articulated prosthesis. It has been designed to eliminate one of the causes of erosion listed (Fig. 2). It has one-millimetre gradations of head diameter size and a constant length from the apex of all sizes of the head unit to the centre of the base of the femoral neck. This constant measurement for all head sizes allows the exact length of neck to be resected at every operation. A buffered impact is obtained by the eight-millimetre thickness of high-density poly-

* The Hastings hip is now made by Messrs Charles Thackray of Leeds, England.

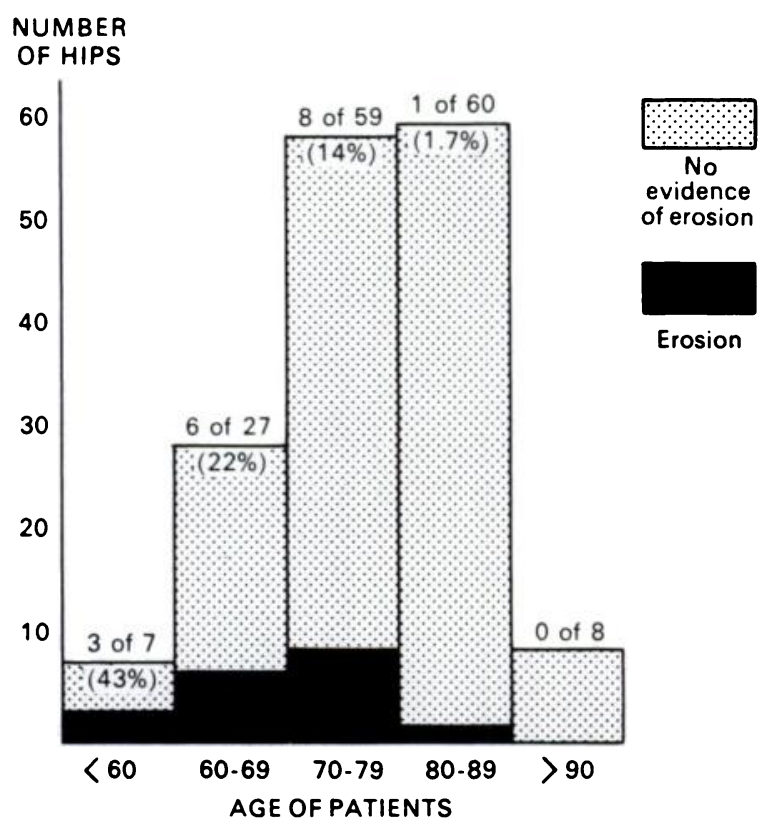

Fig. 1

A histogram showing the incidence of acetabular erosion in a follow-up of 161 Thompson replacements. The overall incidence of erosion was 11 per cent. (From D'Arcy and Devas, $J$ Bone Joint Surg [Br] 1976;58-B:283.) 


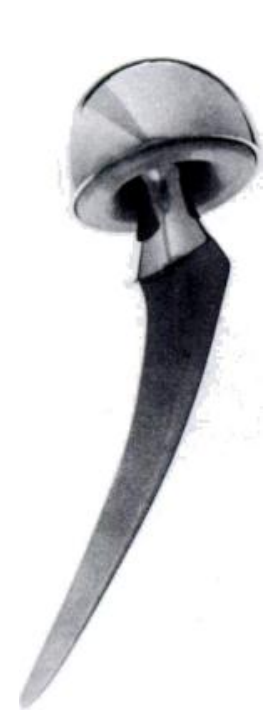

Fig. 2

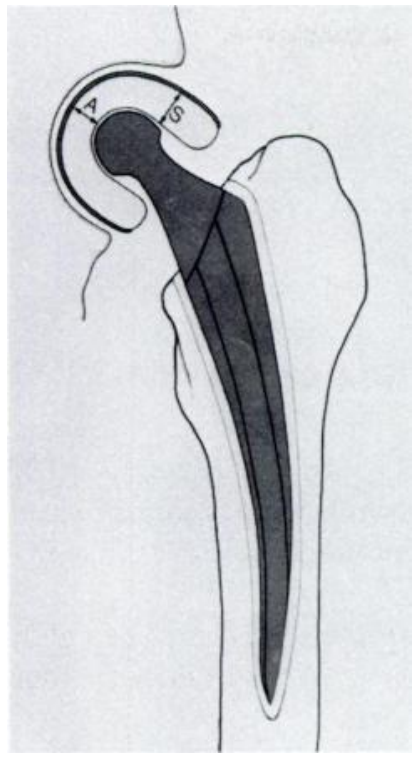

Fig. 3
Figure 2-The Hastings hip assembled. Figure 3-The prosthesis in longitudinal section: the thickness of the high-density polyethylene is greater at the side $(S)$ than at the apex $(A)$.

ethylene covered by a steel outer shell two millimetres thick. This constitutes the outer head which articulates with the head of the femoral portion (Fig. 3). Because the thickness of the high-density polyethylene is always greater at the periphery than at the apex, the cup moves with weight-bearing and its position varies to keep the thinnest portion in the line of force through the hip (Figs 4 and 5). Because the head moves in the acetabulum any minor discrepancy in fit will be taken up by this movement and weight-bearing distributed in a more natural manner. Movement at the interprosthetic articulation is within an arc of 48 degrees.
The head of the femoral stem is the same size as that of the Charnley prosthesis (22.25 millimetre diameter); we are indebted to the late Sir John Charnley for permission to use this size. Should revision to a total hip replacement be needed a Charnley-type acetabular component can be inserted without having to remove the femoral component.

The operation. The anterolateral approach has been the standard approach in this unit over many years and has been used in this trial because it enjoys a low rate of dislocation after operation.

The trial. Before a new prosthesis is allowed into general use it should first be tried by the designer and, after a suitable number have been assessed, field trials at other centres are started (Sweetnam 1981). Figure 6 shows that after an initial batch of 28 had proved satisfactory for at least one year, the new hip was put into increasing use. Up to the end of July 1981, 213 hips had been treated in this way, of which 161 were for fractures, the remaining 52 for arthritis. A reasonable distribution of both groups of patients was maintained throughout the major part of the trial. Beyond mentioning here that this prosthesis gives very satisfactory results for arthritis of the hip in which the acetabulum has retained its shape, and that none developed acetabular erosion, these 52 hips will not be considered further. Table I gives the material in this series. The Thompson prosthesis, which was previously used, is now considered obsolete at Hastings.

As may be expected in this older age group, many patients succumb naturally and, in various series, 14 to 39 per cent of such patients are dead within six months (D'Arcy and Devas 1976). In this series, 19.3 per cent of the patients with fractures died before six months.

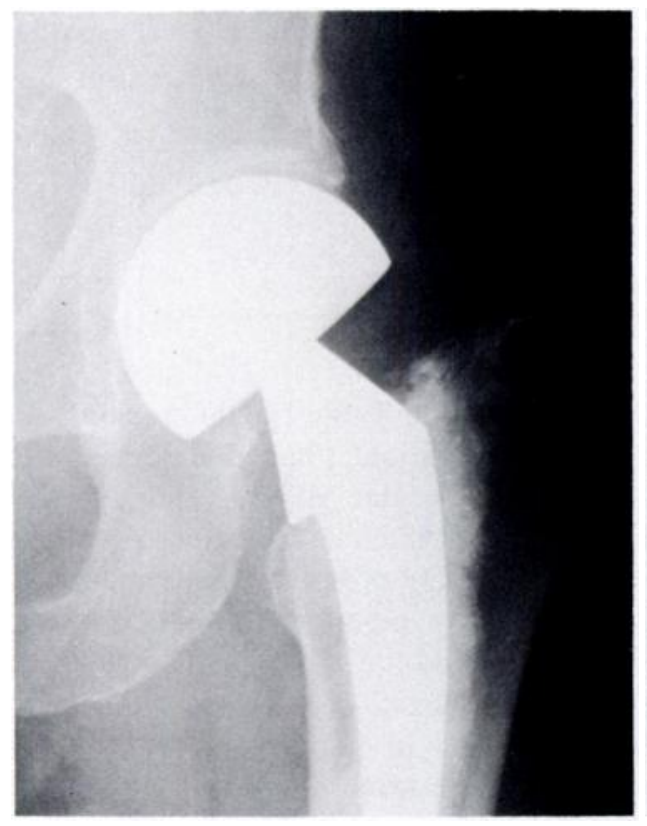

Fig. 4

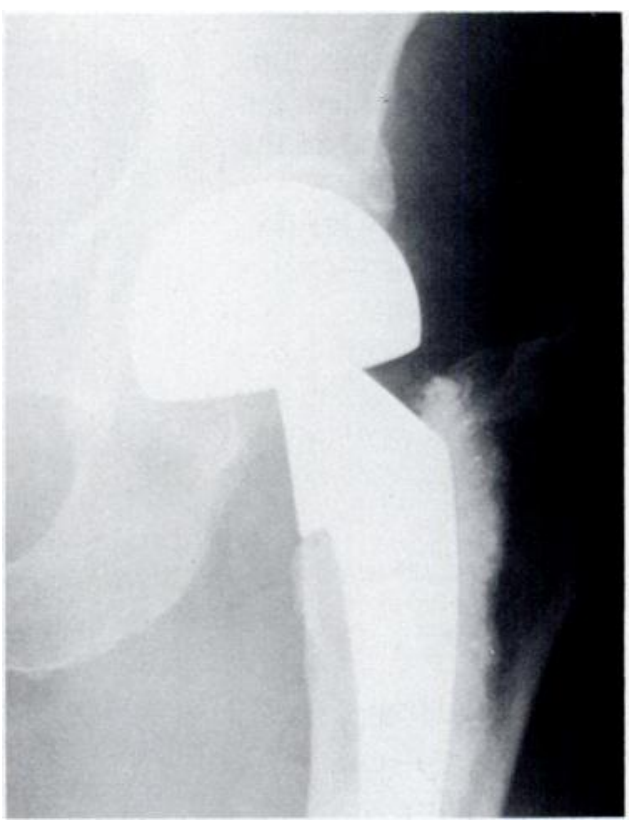

Fig. 5
Figure 4-A hip two years after replacement with the hip adducted but without putting weight through the hip joint: the cup has remained in the abducted position. Figure 5With no further movement but with weight taken through the hip, the cup has reorientated itself to the line of force and has taken up the "umbrella" position on the femoral component. 


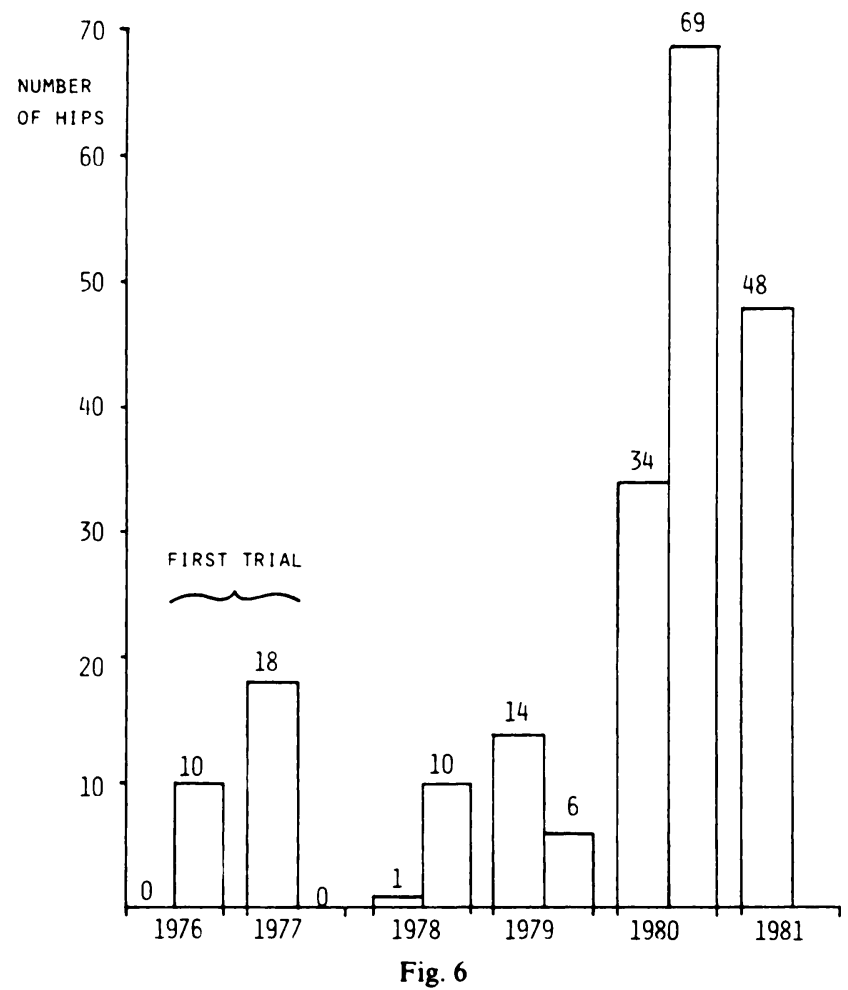

A histogram showing the numbers of operations performed in sixmonthly blocks up to the end of June 1981. Three hips replaced in July 1981 are omitted for clarity.

\section{RESULTS}

A result was considered excellent if the hip flexed over 90 degrees, with no pain or limp with the use of one cane. All patients are told to use a cane after a fracture near the hip. The result was good if the patient had over 60 degrees of flexion in the hip but with occasional slight pain with one cane out of doors. A fair result was the same as a good result except for the use of two sticks or similar aids to walking. Any patient who was worse than fair was considered a failure.

Table I shows that of the total of 213 Hastings hips put into patients, 161 were for fractures of the femoral neck or problems arising therefrom. An example of the

Table I. Patients receiving Hastings hips, September 1976 to July 1981

\begin{tabular}{|lc|}
\hline $\begin{array}{l}\text { Number of operations } \\
\text { Number of patients }\end{array}$ & 213 \\
Number of cases of osteoarthritis & 52 \\
Fractures & \\
Number of fractures & 161 \\
& $(15$ in men, 146 in women) \\
Average age of patients & $\begin{array}{c}78 \text { years } \\
\text { (range 43-95 years) }\end{array}$ \\
Deaths at one month & 14 (8.7 per cent) \\
Total deaths before review (July 1981) & $54^{*}$ (33.5 per cent) \\
\hline
\end{tabular}

* There was one further death up to July 1982

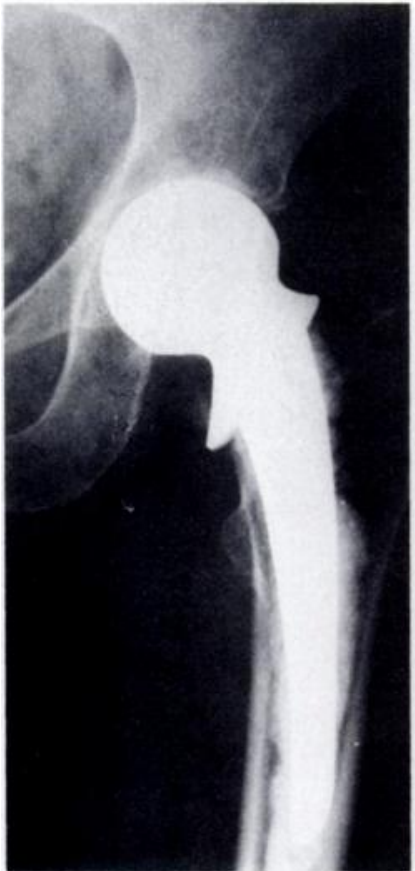

Fig. 7

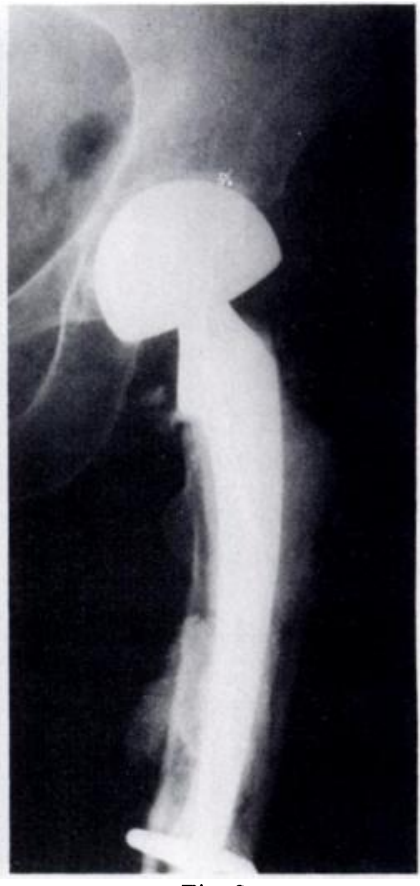

Fig. 8
Case 121. A woman of 74 years had a fractured neck of femur which was treated by a Thompson prosthesis. This started to erode (Fig. 7) and at revision the acetabulum was found to be smooth and a Hastings hip was inserted. A year later (Fig. 8) the patient had obtained a good result with no further acetabular erosion.

latter is the patient whose hip is shown in Figures 7 and 8 who was comparatively young and who had developed acetabular erosion after a Thompson replacement for a fracture. No further erosion has occurred two years after revision with the Hastings hip.

Table II. Results in 97 hips with fractures (with a follow-up of one year or more up to July 1982)

\begin{tabular}{|c|c|c|}
\hline Result & Number & Per cent \\
\hline Excellent & 597 & \multirow{2}{*}{72.2} \\
\hline Good & $11 J$ & \\
\hline Fair & 16 & 16.5 \\
\hline Unsatisfactory & 6 & 6.2 \\
\hline Dislocated & 5 & 5.1 \\
\hline
\end{tabular}

The results are shown in Table II. No erosion was seen to occur in any patient, but one developed condensation of the trabeculae at the apex of the acetabulum (Figs 9 and 10) which later cleared. Five hips failed (Table III). Two of the prototypes had interprosthetic dislocation caused by imperfect correlation of the sizes of the femoral head and the high-density polyethylene. One dislocation occurred after resuscitation for asystole. Another patient, in geriatric care, had an adduction deformity of the same hip which dislocated some weeks after operation. 


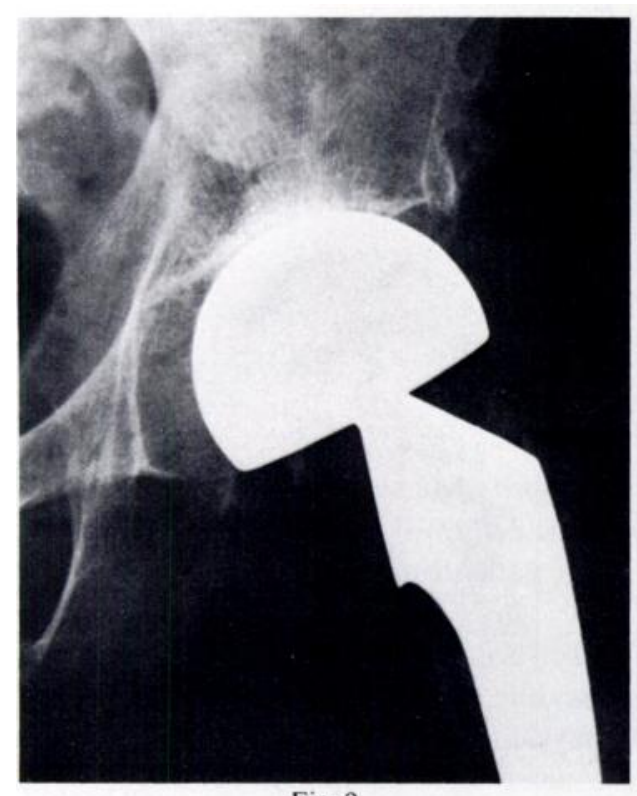

Fig. 9

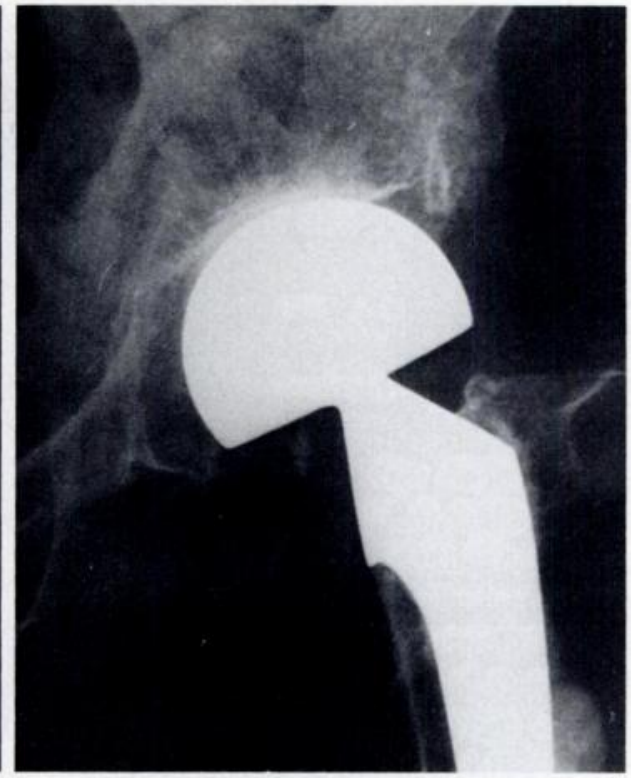

Fig. 10
Case 23. A woman of 81 years broke the neck of her left femur and a prototype Hastings hip was inserted (Fig. 9). Initial erosion, seen as a condensation of trabeculae, diminished over a period of 15 months and no further erosion occurred (Fig. 10).
Table III. Failures

$$
\begin{array}{ll}
\text { Case } 3 & \begin{array}{l}
\text { Early prototype. Interprosthetic dislocation. } \\
\text { Girdlestone. Refused further operation. }
\end{array} \\
\text { Case 11 } & \begin{array}{l}
\text { Early prototype. Dislocated. Converted to Charnley } \\
\text { total hip replacement. Did well. }
\end{array} \\
\text { Case } 86 & \text { Revised and satisfactory. } \\
\text { Case 147 } & \begin{array}{l}
\text { Elderly bedridden patient with severe adduction } \\
\text { deformity. Patient died shortly after operation. }
\end{array} \\
\text { Case 199 } & \begin{array}{l}
\text { Inserted for fracture-dislocation. Dislocated } \\
\text { immediately after operation in Intensive Care Unit. } \\
\text { Reduced. Excellent function. }
\end{array}
\end{array}
$$

\section{DISCUSSION}

The fractured femoral neck places a considerable strain on the resources of many orthopaedic departments, especially in those areas, such as Hastings, with a high density of elderly people; thus a policy of management has had to be evolved to prevent beds being blocked (Devas 1977). The principle of treatment of fractures of the femoral neck in the elderly is by prosthetic head replacement in nearly all cases.

In this early series there has been no acetabular erosion seen with the Hastings hip. Erosion is easiest to see radiographically, starting as a condensation of the bony trabeculae at that part of the acetabulum that is taking the greatest polar force. In one patient, condensation of trabeculae occurred as though erosion would follow (Figs 9 and 10). After six months, however, the trabeculae were less apparent and bone texture continued to improve. The dynamic movement inherent in the design of the Hastings hip may have assisted in this improvement, continually altering the position of loadbearing to different parts of the acetabulum.

Another patient, who had had a Thompson replacement for a fractured neck of femur, developed marked acetabular erosion. At revision the eroded acetabulum was smooth and a Hastings hip was introduced (Figs 7 and 8). After one year no further erosion had occurred and the acetabular profile appeared to have improved. The patient, who had a slight limp and some occasional aching, was classed as having a good result.

The results, on reviewing the patients, showed that the hips were as comfortable as after a Thompson or Austin Moore replacement and that, in general, the movement of the hip was better. It is neither fruitful nor possible to assess the elderly in too much detail in regard to range of movement and level of activity because of the concomitant problems that beset them.

The object of this new hip appears to have been attained and acetabular erosion has been prevented.

We are grateful to the Editor of the Journal of Bone and Joint Surgery (British volume) for allowing us to reproduce the histogram in Figure 1. We are also grateful to Messrs J. D. Spencer, FRCS, MRCP, John C. D'Arcy, FRCS, D. J. Richards, FRCS, E. H. Compton, FRCS and W. M. Lennox, FRCS, for being willing to take part in the field trials and we are also grateful to Mrs E. Pallot, Mrs A. Caswell and Mrs A. Capjon for secretarial and assessment assistance. Finally, we wish to thank Mr Harry Gower, senior medical physics technician, for his great skill in making the first models of the Hastings hip.

\section{REFERENCES}

Barnes R, Brown JT, Garden RS, Nicoll EA. Subcapital fractures of the femur: a prospective review. J Bone Joint Surgery [Br] 1976:58-B: 2-24. D'Arcy J, Devas M. Treatment of fractures of the femoral neck by replacement with the Thompson prosthesis. J Bone Joint Surg [Br] 1976; 58-B: 279-86.

Devas M. Geriatric orthopaedics. London: Academic Press, 1977.

Sweetnam DR. A surveillance scheme with "Recommended List" of artificial joints. Health Trends 1981:13:43-4. 